\title{
An unusual case of dysuria, pollakisuria, and eosinophilia: Answers
}

\author{
Fabian Eibensteiner ${ }^{1}$ (D) - Ursula Tonnhofer ${ }^{2} \cdot$ Alexander Springer $^{2}$ (I) $\cdot$ Hubert Kogler $^{3} \cdot$ Leila Ronceray $^{3}$. \\ Azadeh Hojreh ${ }^{4} \cdot$ Christoph Aufricht $^{1}$ (D) $\cdot$ Krisztina Rusai $^{1}$ (D)
}

Received: 27 April 2021 / Accepted: 7 May 2021 / Published online: 18 November 2021

(C) The Author(s) 2021

Keywords Eosinophilic cystitis $\cdot$ Celiac disease $\cdot$ Eosinophilia $\cdot$ Cystitis $\cdot$ Cystic mass $\cdot$ Pediatric

\section{Abbreviations \\ PDGFRA Platelet-derived growth factor receptor alpha \\ PDGFRB Platelet-derived growth factor receptor beta \\ FGFR1 Fibroblast growth factor receptor 1}

\section{Answers}

\section{What is the diagnosis and what is its most likely etiology?}

The patient has eosinophilic cystitis, which developed due to eosinophilia triggered by celiac disease.

This is the first case in the current literature of a pediatric patient with celiac disease and concomitant symptomatic eosinophilic cystitis. Until now, only associations of celiac disease with peripheral blood eosinophilia and eosinophilic esophagitis in pediatric patients, as well as one association of an adult patient with eosinophilic cystitis, have been reported $[1,2]$.

This refers to the article that can be found at https://doi.org/10.1007/ s00467-021-05128-2.

Krisztina Rusai

krisztina.heindl-rusai@meduniwien.ac.at

1 Division of Pediatric Nephrology and Gastroenterology,

Comprehensive Center for Pediatrics, Medical University of Vienna, Waehringer Guertel 18-20, 1090 Vienna, Austria

2 Division of Pediatric Surgery, Comprehensive Center for Pediatrics, Medical University of Vienna, Vienna, Austria

3 Department of Pediatrics and Adolescent Medicine, St. Anna Children's Hospital, Medical University of Vienna, Vienna, Austria

4 Department of Biomedical Imaging and Image-guided Therapy, Medical University of Vienna, Vienna, Austria
The true etiology in many cases of eosinophilic cystitis remains elusive to this day, with several associations with hypereosinophilic syndromes, allergies, medications, and even with bladder trauma, especially in response to bladder catheterization [3, 4]. Under normal conditions, eosinophils are mainly found in the bone marrow, lymphoid organs, the mucosa of the gastrointestinal tract, and the uterus, but very rarely in other organ tissues. Secondary (reactive) eosinophilia is mainly driven by cytokines, whereas primary (clonal) forms of eosinophilia are mostly caused by tyrosine kinase gene fusions, involving the coding genes for platelet-derived growth factor receptor alpha (PDGFRA), beta (PDGFRB), or fibroblast growth factor receptor 1 (FGFRI). Secondary (reactive) eosinophilia has multiple causes, such as allergy, drugs, and parasitic disease, and respiratory, gastrointestinal, and rheumatologic disorders $[1,5,6]$.

Overall, eosinophilic cystitis is a rare inflammatory disorder, especially in the pediatric population [3, 4]. It should be noted that the age of disease onset in the case presented here is very early (at 3 years of age) in contrast to currently published case reports, with a median age of disease onset of 6.5 years $[3,6-8]$.

\section{What further examinations should be performed?}

Irrespective of its cause, prolonged or marked activation of eosinophils may lead to migration of eosinophils into other organ tissues, such as the heart, lung, skin, or urinary tract, resulting in tissue and subsequent end-organ damage. Therefore, evaluation for the presence of other end-organ damage is essential. Based on individual signs and symptoms, chest X-ray, electrocardiogram, echocardiography, abdominal ultrasound, tissue biopsies, and other evaluations should be performed $[1,5,6]$.

We have investigated the peripheral blood for genetic mutations (PDGFRA, PDGFRB, FGFRI) for the most frequent primary (clonal) eosinophilic disease, which yielded negative 
results [1]. Thorough workup for other secondary end-organ damages did not reveal further involvement of other organs.

In the absence of an underlying cause of eosinophilia, a bone marrow punction should be performed to rule out a hematological neoplasm.

\section{What is the treatment for this disease?}

The treatment of eosinophilic cystitis is unfortunately not well established - there have been no controlled studies performed to date.

However, many cases in children are self-limiting [3]. First-line treatments typically involve the removal of the driving reason, followed by the use of antihistamines and corticosteroids. The use of transurethral indwelling catheters and surgical treatment have also been reported, although less frequently than in adults [1].

In the case of our patient, upon diagnosis of celiac disease, treatment with a gluten-free diet was initiated. This led to a significant decrease and then to normalization of peripheral eosinophila (3.7\% of peripheral leukocytes and $0.3 \times 10^{9} / \mathrm{L}$ absolute eosinophil count) over the course of 3 months, and a decrease of bladder wall thickening to $0.6 \mathrm{~cm}$ after 6 months on a gluten-free diet. After 9 months of the gluten-free diet, initial symptoms for eosinophilic cystitis were completely relieved, and urinary bladder wall thickening remained at $0.6 \mathrm{~cm}$.

\section{Discussion}

In the case presented here, eosinophilia may be caused by previously undetected celiac disease, leading to secondary (reactive) eosinophilia and subsequent symptomatic end-organ damage of the urinary bladder wall before distinct symptomatic presentation of the underlying gastrointestinal disorder. The percentage of peripheral eosinophilia in patients with celiac disease was reported in small case series only, with $4 / 10$ and $3 / 7$ patients with celiac disease, having peripheral eosinophilia, and eosinophilic esophagitis $[9,10]$. An initial secondary (reactive) eosinophilia of $28 \%$ of peripheral leukocytes probably led to urinary bladder wall infiltration with inflammation causing bladder wall thickening up to $2 \mathrm{~cm}$, which clinically correlated well with the boy's symptoms at the time of diagnosis. This hypothesis is supported by only intermittent recovery upon symptomatic treatment with oxybutynin, and prolonged remission of symptoms, bladder wall formations, and peripheral blood eosinophilia after initiation of a gluten-free diet.

Prognosis of eosinophilic cystitis is difficult to establish, due to very few pediatric cases worldwide. However, most cases are responsive to various treatments, while patients with prior allergic conditions and granulomatous diseases show high rates of recurrence [3]. Therefore, we currently keep this patient on close follow-up at 3-month intervals at our outpatient clinic.

\section{Conclusions}

In conclusion, we are the first to report the case of a 3-year-old boy with celiac disease causing symptomatic eosinophilic cystitis before the onset of gastrointestinal symptoms. Treatment of the underlying condition (celiacfig disease) has led to the resolution of eosinophilia and eosinophilic cystitis.

Acknowledgements The authors are grateful to Dr. Anke Scharrer at the Clinical Institute of Pathology, Medical University of Vienna, for providing information on the histologic specimen, and to Dr. Andreas Vécsei at the Department of Pediatrics and Adolescent Medicine, St. Anna Children's Hospital, Medical University of Vienna, Vienna, Austria, for assistance with manuscript preparation.

Author contribution Dr. F Eibensteiner and Dr. K Rusai drafted the initial manuscript, reviewed, and revised the manuscript and take responsibility for the integrity and accuracy of the data presented. Critical revision of the manuscript for important intellectual content was done by Dr. U Tonnhofer, Dr. A Springer, Dr. A Hojreh, Dr. L Ronceray, Prof Dr Aufricht, and Dr. H Kogler. All authors approved the final manuscript as submitted.

Funding Open access funding provided by Medical University of Vienna.

Availability of data and material No data or additional material is made available.

Code availability No custom codes were used for this study.

\section{Declarations}

Conflict of interest The authors declare no competing interests.

Ethics approval No approval needed in accordance with our local ethics committee.

Consent to participate Not applicable.

Consent for publication Consent for publication was given by each author as well as the patient's caregiver.

Open Access This article is licensed under a Creative Commons Attribution 4.0 International License, which permits use, sharing, adaptation, distribution and reproduction in any medium or format, as long as you give appropriate credit to the original author(s) and the source, provide a link to the Creative Commons licence, and indicate if changes were made. The images or other third party material in this article are included in the article's Creative Commons licence, unless indicated otherwise in a credit line to the material. If material is not included in the article's Creative Commons licence and your intended use is not permitted by statutory regulation or exceeds the permitted use, you will need to obtain 
permission directly from the copyright holder. To view a copy of this licence, visit http://creativecommons.org/licenses/by/4.0/.

\section{References}

1. Butt NM, Lambert J, Ali S, Beer PA, Cross NC, Duncombe A, Ewing J, Harrison CN, Knapper S, McLornan D, Mead AJ, Radia D, Bain BJ, British Committee for Standards in Haematology (2017) Guideline for the investigation and management of eosinophilia. Br J Haematol 176:553-572. https://doi.org/10.1111/bjh. 14488

2. Popescu OE, Landas SK, Haas GP (2009) The spectrum of eosinophilic cystitis in males: case series and literature review. Arch Pathol Lab Med 133:289-294. https://doi.org/10.1043/15432165-133.2.289

3. Sparks S, Kaplan A, DeCambre M, Kaplan G, Holmes N (2013) Eosinophilic cystitis in the pediatric population: a case series and review of the literature. J Pediatr Urol 9:738-744. https://doi.org/ 10.1016/j.jpurol.2012.11.004

4. Zhou AG, Amin A, Yates JK, Diamond DA, Tyminski MM, Badway JA, Ellsworth PI, Aidlen JT, Owens CL (2017) Mass forming eosinophilic cystitis in pediatric patients. Urology 101: 139-141. https://doi.org/10.1016/j.urology.2016.11.002
5. Shomali W, Gotlib J (2019) World Health Organization-defined eosinophilic disorders: 2019 update on diagnosis, risk stratification, and management. Am J Hematol 94:1149-1167. https://doi.org/10. 1002/ajh.25617

6. van den Ouden D (2000) Diagnosis and management of eosinophilic cystitis: a pooled analysis of 135 cases. Eur Urol 37:386-394. https://doi.org/10.1159/000020183

7. Bey E, Teklali Y, Rabattu PY, Lapierre SG, Piolat C (2017) Case: Eosinophilic cystitis presenting as a bladder mass in an 11-year-old girl. Can Urol Assoc J 11:E446-E448. https://doi.org/10.5489/cuaj. 4513

8. Cohen J, Letavernier B, Garel C, Boubnova J, Boudjemaa S, Bensman A (2011) Eosinophilic cystitis in children. Arch Pediatr 18:550-552. https://doi.org/10.1016/j.arcped.2011.02.021

9. Hommeida S, Alsawas M, Murad MH, Katzka DA, Grothe RM, Absah I (2017) The association between celiac disease and eosinophilic esophagitis: Mayo experience and meta-analysis of the literature. J Pediatr Gastroenterol Nutr 65:58-63. https://doi.org/10. 1097/MPG.0000000000001499

10. Ooi CY, Day AS, Jackson R, Bohane TD, Tobias V, Lemberg DA (2008) Eosinophilic esophagitis in children with celiac disease. J Gastroenterol Hepatol 23:1144-1148. https://doi.org/10.1111/j. 1440-1746.2007.05239.x

Publisher's note Springer Nature remains neutral with regard to jurisdictional claims in published maps and institutional affiliations. 